\title{
FROM THE EDITORS: WHAT GROUNDED THEORY IS NOT
}

\author{
ROY SUDDABY \\ University of Alberta
}

Editor's Note. Three years ago, I invited Robert (Bob) Gephart to write a "From the Editors" column designed to help authors improve their chances of success when submitting qualitative research to $A M J$. Judging from the increasing number of qualitative studies that have been accepted and published in $A M J$ since that time, I would like to think that his article, "Qualitative Research and the Academy of Management Journal," has had a positive impact.

Continuing in this tradition, I asked Roy Suddaby-an excellent reviewer (and author) of qualitative research-to tackle another "big issue" that the editorial team has noticed with respect to qualitative submissions to $A M$ J: overly generic use of the term "grounded theory" and confusion regarding alternative epistemological approaches to qualitative research. Like Bob before him, Roy has, I believe, produced an analysis that will greatly benefit those who are relatively new to qualitative research or who have not yet had much success in getting their qualitative research published. Hopefully, Roy's analysis will help even more authors to succeed, thus allowing $A M J$ and other journals to continue to increase the quality of insights provided by rich qualitative studies of individual, organizational, and institutional phenomena.

Sara L. Rynes

I was not particularly surprised to observe that most of the articles identified as "interesting research" in a recent $A M J$ survey were the product of qualitative methods (Bartunek, Rynes, \& Ireland, 2006). New discoveries are always the result of high-risk expeditions into unknown territory. Darwin, Columbus, and Freud, each in different ways, were conducting qualitative inquiries.

I am continually surprised, however, by the profound misunderstanding of what constitutes qualitative research. Such confusion is most apparent when authors claim to be using "grounded theory."

Thanks to Sara Rynes for suggesting and commenting on this paper. Thanks also to Chet Miller, Jean Bartunek, Kristine Fitch, Chris Quinn-Trank, and Marvin Washington for very helpful comments on early drafts.
In the manuscripts I review for $A M J$ I have seen the term "grounded theory" used to describe analysis via correlations, word counts, and pure introspection. I am not suggesting that these techniques cannot be used in a grounded theory study. But I note, with some concern, that "grounded theory" is often used as rhetorical sleight of hand by authors who are unfamiliar with qualitative research and who wish to avoid close description or illumination of their methods. More disturbing, perhaps, is that it becomes apparent, when one pushes them to describe their methods, that many authors hold some serious misconceptions about grounded theory.

What are these misconceptions? Before reviewing them, I offer you a short description of what grounded theory is. Like most difficult subjects, grounded theory is best understood historically. The methodology was developed by Glaser and Strauss (1967) as a reaction against the extreme positivism that had permeated most social research. They disputed the view that the social and natural sciences dealt with the same type of subject matter. Specifically, Glaser and Strauss challenged prevalent assumptions of "grand theory," the notion that the purpose of social research is to uncover preexisting and universal explanations of social behavior. In making their challenge, Glaser and Strauss looked to the pragmatism of Charles Saunders Peirce (1839-1914) and early symbolic interactionists, particularly George Herbert Mead (1863-1931) and Charles Cooley (1864-1929), each of whom rejected the notion that scientific truth reflects an independent external reality. Instead, they argued that scientific truth results from both the act of observation and the emerging consensus within a community of observers as they make sense of what they have observed. In this pragmatic approach to social science research, empirical "reality" is seen as the ongoing interpretation of meaning produced by individuals engaged in a common project of observation.

Glaser and Strauss (1967) proposed grounded theory as a practical method for conducting research that focuses on the interpretive process by analyzing the "the actual production of meanings and concepts used by social actors in real settings" (Gephart, 2004: 457). They argued that new theory could be developed by paying careful attention to 
the contrast between "the daily realities (what is actually going on) of substantive areas" (Glaser \& Strauss, 1967: 239) and the interpretations of those daily realities made by those who participate in them (the "actors"). They also rejected positivist notions of falsification and hypothesis testing and, instead, described an organic process of theory emergence based on how well data fit conceptual categories identified by an observer, by how well the categories explain or predict ongoing interpretations, and by how relevant the categories are to the core issues being observed. Most significantly, Glaser and Strauss offered a compromise between extreme empiricism and complete relativism by articulating a middle ground in which systematic data collection could be used to develop theories that address the interpretive realities of actors in social settings.

The method described by Glaser and Strauss (1967) is built upon two key concepts: "constant comparison," in which data are collected and analyzed simultaneously, and "theoretical sampling," in which decisions about which data should be collected next are determined by the theory that is being constructed. Both concepts violate longstanding positivist assumptions about how the research process should work. Constant comparison contradicts the myth of a clean separation between data collection and analysis. Theoretical sampling violates the ideal of hypothesis testing in that the direction of new data collection is determined, not by a priori hypotheses, but by ongoing interpretation of data and emerging conceptual categories.

Grounded theory, therefore, is a method that is more appropriate for some questions than others. Clearly, it is most suited to efforts to understand the process by which actors construct meaning out of intersubjective experience. Grounded theory should also be used in a way that is logically consistent with key assumptions about social reality and how that reality is "known." It is less appropriate, for example, to use grounded theory when you seek to make knowledge claims about an objective reality, and more appropriate to do so when you want to make knowledge claims about how individuals interpret reality.

Such fine distinctions between abstract categories are perhaps more easily seen through concrete examples. From my reviewing experience for $A M J$ and other management journals, I have identified six common misconceptions about grounded theory. Although I make no claim that these categories are exhaustive, they accurately reflect my experience and offer, I think, a reasonable assessment of common errors researchers make in conducting and presenting grounded theory research.

\section{SIX COMMON MISCONCEPTIONS}

\section{Grounded Theory Is Not an Excuse to Ignore the Literature}

A common misassumption is that grounded theory requires a researcher to enter the field without any knowledge of prior research. There are several variants of this myth, each based on the false premise that the researcher is a blank sheet devoid of experience or knowledge. An extreme variant is the notion that not only must the researcher enter the field with a blank mind (i.e., without knowledge of the literature and absent prior experience), but that she or he must also enter the field with a blank agenda (i.e., without a defined research question). A less extreme, but more problematic, version suggests that the researcher must defer reading existing theory until the data are collected and analyzed. This notion is reflected in manuscripts whose authors avoid any mention of prior literature until their papers' discussions or concluding sections. In a similar variant, researchers use grounded theory to tackle a subject that is in "well-tilled soil" - that is, a subject that has attracted a long and credible history of empirical research-and use grounded theory as a justification for ignoring prior research in formulating their study.

Leaving aside the question of whether it is even possible to disregard one's prior knowledge and experience, the idea that reasonable research can be conducted without a clear research question and absent theory simply defies logic. Such research, as Ronald Coase famously observed, is likely to produce a random "mass of descriptive material waiting for a theory, or a fire" (Coase, 1988: 230). Totally unstructured research produces totally unstructured manuscripts that are unlikely to make it past the desk editor at any credible journal of social science.

The notion of using grounded theory as an excuse to forgo examining extant literature is perhaps more problematic because it is often based on a researcher's desire to discover something new. This desire most often manifests when researchers use grounded theory to tackle well-established areas of empirical inquiry-leadership, for example. In most cases, the researchers honestly hope to gain fresh insights by keeping out of the ruts early travelers have worn. They thus avoid formal reviews of relevant literature in their manuscripts to create the impression that their observations and analytic categorizations of data were not colored by previous ideas.

Unfortunately, this approach is also based on a serious misreading of the seminal texts in grounded methodology. Although Glaser and Strauss were 
motivated against grand theory, their formulation of grounded theory was never intended to encourage research that ignored existing empirical knowledge. They distinguished between substantive theory, or theory grounded in extant research in a particular subject area (e.g., leadership), and grounded theory, but they observed a direct and necessary link between the two forms of theory:

Substantive theory is a strategic link in the formulation and generation of grounded formal theory. We believe that although formal theory can be generated directly from data, it is more desirable, and usually necessary, to start the formal theory from a substantive one. The latter not only provides a stimulus to a "good idea" but it also gives an initial direction in developing relevant categories and properties and in choosing possible modes of integration. Indeed it is difficult to find a grounded formal theory that was not in some way stimulated by substantive theory. (Glaser \& Strauss, 1967: 79)

The real danger of prior knowledge in grounded theory is not that it will contaminate a researcher's perspective, but rather that it will force the researcher into testing hypotheses, either overtly or unconsciously, rather than directly observing. Grounded theory methodologists describe a number of ways to prevent this from happening. One is to avoid research that adheres too closely to a single substantive area and, instead, draw from the several substantive areas that are frequently reflected in a given daily reality. Stephen Barley's (1986, 1990) research on technology and structuring, for example, succeeds because it draws from (at least) two areas of substantive research-technological change and structuration theory-that are both often germane in the same research contexts. Another technique is to be continuously aware of the possibility that you are being influenced by preexisting conceptualizations of your subject area. Particularly when working through well-tilled soil, grounded theorists must retain the capacity to "make the familiar strange" (Spindler \& Spindler, 1982). A final solution is to try not to overextend the objective of grounded theory research. That is, researchers may shoot for "the elaboration of existing theory" rather than untethered "new" theory.

None of these approaches justifies ignorance of existing literature or knowledge. The reality of grounded theory research is always one of trying to achieve a practical middle ground between a theory-laden view of the world and an unfettered empiricism. A simple way to seize this middle ground is to pay attention to extant theory but constantly remind yourself that you are only human and that what you observe is a function of both who you are and what you hope to see.

\section{Grounded Theory Is Not Presentation of Raw Data}

I occasionally see papers that start with an appropriate and interesting question, are written well, and follow a well-constructed method, but produce findings that are obvious or trite. You've seen such papers; they conclude that entrepreneurs are risk takers, change is difficult, and leaders are charismatic. The common thread in such research is that it tends to present incomplete or relatively undigested data.

This unfortunate outcome is usually the result of one of three errors in the practice of grounded theory research. First, there may be some confusion between grounded theory and phenomenology. Phenomenological research emphasizes the subjective experiences of actors" "lifeworlds" (Husserl, 1969; Schutz, 1972). Methodologically, phenomenologists attempt to capture the rich, if not mundane, detail of actors' lived experiences. They often present data in relatively raw form to demonstrate their authenticity and to permit a holistic interpretation of the subjects' understanding of experience. Such data are typically analyzed through somewhat introspective techniques that permit a clear focus on the relationship between the language used and the objects to which language relates (Moustakas, 1994).

Although grounded theory retains some sympathy for phenomenological assumptions and techniques, researchers using grounded theory are less focused on subjective experiences of individual actors per se and are instead more attentive to how such subjective experiences can be abstracted into theoretical statements about causal relations between actors. The difference between these two approaches can be seen in how each uses the technique of interviewing. In a phenomenological study, in-depth interviews are a key means of probing individuals' subjective experiences (Wimpenny \& Gass, 2000). The detail and nuance of the stories interviewees elaborate and the specific words they choose comprise the primary unit of analysis. Because phenomenology is an effort to probe the lived experience of subjects without contaminating the data (Moustakas, 1994), units of data are often presented in their raw form. In grounded theory, by contrast, interviews with subjects may start with a phenomenological interest in subjective understandings, but the primary interest is not in the stories themselves. Rather, they are a means of eliciting information on the social situation under examination. In contrast to phenomenological studies, grounded theory studies rarely have interviews as their sole form of data collection. 
The second grounded theory application error that I see as producing obvious and trite output is failure to "lift" data to a conceptual level. Again, this failure may arise from the epistemological problem of confusing grounded theory with phenomenology. It is more likely, however, that the researcher has simply failed to completely analyze the data. A key element of grounded theory is identifying "a slightly higher level of abstractionhigher than the data itself" (Martin \& Turner, 1983: 147. The movement from relatively superficial observations to more abstract theoretical categories is achieved by the constant interplay between data collection and analysis that constitutes the constant comparative method. The failure of data to coalesce into definable conceptual structures that move beyond the obvious may well be the result of a researcher's failure to thoroughly work between data and extant knowledge in an effort to find the best fit or the most plausible explanation for the relationships being studied (Locke, 2001).

Finally, the researcher who has produced simplistic output may simply have stopped collecting data too early. Unlike more traditional, positivist research, grounded theory offers no clean break between collecting and analyzing data. Rather, a researcher must continue to collect data until no new evidence appears. This process, called "category saturation," is one of the primary means of verification in grounded theory (Strauss \& Corbin, 1998). Premature departure from the field may well result in data that are only partly analyzed and therefore fail to elevate obvious categorizations to a more abstract theoretical level.

\section{Grounded Theory Is Not Theory Testing, Content Analysis, or Word Counts}

I regularly see papers in which the authors attempt to use grounded theory methods to test hypotheses. These fall into a larger category of manuscripts whose authors have engaged in the sloppy practice of methodological slurring (Goulding, 2002), using interpretive methods to analyze "realist" assumptions. In most cases the manuscripts begin with clear sets of positivist assumptions, including hypotheses, and then proceed to report "tests" of the hypotheses with sets of interviews or counts of words in relevant publications. In other cases manuscripts will start with interpretive premises, such as the social construction of reputation in the popular business press, and then report word counts, with the claim of having performed grounded theory.

Although there is nothing wrong with combining qualitative and quantitative methods-in fact, the practice should be encouraged-there must be some degree of congruence between the research question (i.e., a researcher's assumptions about the nature of reality and how one might know reality) and the methods used to address the question. A realist ontology rests on the assumption that the variables of interest exist outside individuals and are, therefore, concrete, objective, and measurable (Burrell \& Morgan, 1979). An "interpretivist” ontology rests on the contrasting assumption that human beings do not passively react to an external reality but, rather, impose their internal perceptions and ideals on the external world and, in so doing, actively create their realities (Morgan \& Smircich, 1980). From this perspective, the key variables of interest are internal and subjective.

Keep in mind that the purpose of grounded theory is not to make truth statements about reality, but, rather, to elicit fresh understandings about patterned relationships between social actors and how these relationships and interactions actively construct reality (Glaser \& Strauss, 1967). Grounded theory thus should not be used to test hypotheses about reality, but, rather, to make statements about how actors interpret reality. As Martin and Turner (1986) observed, grounded theory is best used when no explicit hypotheses exist to be tested, or when such hypotheses do exist but are too abstract to be tested in a logical, deductive manner. This is where grounded theory is most appropriatewhere researchers have an interesting phenomenon without explanation and from which they seek to "discover theory from data" (Glaser \& Strauss, 1967: 1).

There are some qualifications to my statement that grounded theory is not theory testing, content analysis, or word counts. Although grounded theorists do not use Popperian notions of falsification as a technique for making statements about reality, they do "test" their tentative ideas and conceptual structures against ongoing observations. A key component of the constant comparative method is such critical evaluation of emerging constructs against ongoing observations. Similarly, although grounded theory is not to be confused with content analysis or word counting, both techniques can form part of grounded theory studies. The important difference is that grounded theory describes an overall method for systematically gathering and analyzing data, but content analysis describes a specific context within which a distinct type of data can be gathered and analyzed. Typically, in a grounded theory study, content analysis is only one of multiple contexts for acquiring data. Word counting, which is a subset of content analysis, is somewhat more problematic in that it bears posi- 
tivist assumptions about the relationship between word frequency and meaning, most of which violate the interpretivist assumptions of grounded theory (Krippendorff, 2003).

Another important qualification to my comments about methodological slurring arises from the way in which grounded theory tends to be presented in journal articles. Even though grounded theory research is conducted iteratively, by analyzing and collecting data simultaneously, it is usually presented sequentially. This gap occurs because the norms of presentation in management (and other academic) journals have positivist origins and impose discrete and sequential categories of data collection and analysis on authors trying to present grounded theory research. In pure form, grounded theory research would be presented as a jumble of literature consultation, data collection, and analysis conducted in ongoing iterations that produce many relatively fuzzy categories that, over time, reduce to fewer, clearer conceptual structures. Theory would be presented last.

Presenting grounded theory in this pure form, however, would be neither efficient nor comprehensible to the majority of researchers who work in the positivist paradigm. The norm that has evolved is to present grounded theory in the traditional discrete categories and in the same sequence as quantitative research: theory, data collection, data analysis, results. Doing so has the unfortunate consequence of creating the impression of methodological slurring, even when the constant comparative method has been used. For those unfamiliar with grounded theory techniques, the mode of presentation may also create the unfortunate impression that grounded theory methods can be mixed with a positivist research agenda.

There are ways of avoiding this incorrect impression while adhering to the sequential norms of journal presentation. Foremost, the process of data analysis, including coding techniques and category creation, should be made apparent to the reader. Authors can do this in their methods sections and, in my opinion, such accounts are most effective when the authors provide illustrative examples of coding techniques and the evolution of conceptual categories in a table or appendix.

Similarly, authors can note that, although they are presenting theoretical concepts in a traditional manner (i.e., up front in the study), the concepts did, in fact, emerge from the study. Perhaps one of the most eloquent versions of this statement came from a manuscript recently reviewed in the Academy of Management Journal:
In framing our introduction and the following conceptual overviews, we have employed the theoretical concepts that actually emerged from the study. In the grounded, interpretive research approach used here, the theoretical concepts and framework are grounded in and emerge from the data and analysis that follow (Glaser \& Strauss, 1967; Strauss and Corbin, 1990), rather than being derived from prior theory that guided data collection and analysis. A "purist" rendition of interpretive research reporting would, however, entail a lengthy and complex qualitative data presentation before the reader learns what the major theoretical dimensions and contributions are likely to be. In other words, the theory would normally appear after the data presentation (Dact, 1985). We suspend this interpretive reporting hallmark for the sake of advance clarity, and employ the more traditional presentational strategy of providing a theoretical overview first, to preview the major findings and resulting model. It is important to keep in mind, however, that these concepts actually emerged from the study itself (along with consultations with relevant literature that were guided by the emerging thematic analysis). (Anonymous, provided by editor)

I like this caveat to the presentation of grounded theory because it succinctly avoids the impression of methodological slurring by identifying the messy, nonlinear reality of grounded theory research and, simultaneously, providing a practical justification (i.e., comprehensibility) for presenting the data and analysis in a traditional "sanitized" format.

The key objection to mixing grounded theory with hypothesis testing, however, is that doing so tends to violate the notion of theoretical emergence. That is, when a researcher uses grounded theory techniques to "test" preconceived notions of what is likely to be observed, chances are he or she will "see" the intended categories and overlook more emergent ones. This form of methodological slurring tends toward "forced categories" in the coding process (Glaser, 1992) and reduces grounded theory technique from its intended purpose of identifying new theory to one of simply confirming extant understandings of a social phenomenon as a consequence of the researcher imposing intentions on the data.

\section{Grounded Theory Is Not Simply Routine Application of Formulaic Technique to Data}

Some manuscripts reinforce the myth that grounded theory is a relatively mechanical technique. This myth has several manifestations. One is to present grounded theory as a series of rigid rules, such as "saturation is achieved when one has con- 
ducted between 25 and 30 interviews." Another is the implication that pouring textual data into a software package will yield results. A common characteristic of most efforts to use grounded theory is a neurotic overemphasis on coding. The researcher has diligently followed the rules and gone from open coding (derived from an initial reading of the data) to more abstract or categorical codes and finally to conceptual or theoretical codes but has made no interpretive effort at any stage of coding. The result is typically a nice set of conceptual categories that, in the process of routine data analysis, become divorced from both the data and the original research question. That is, although the rigid application of grounded theory technique might produce passable results, such a mechanical approach usually lacks the spark of creative insight upon which exemplary research is based.

The key issue to remember here is that grounded theory is an interpretive process, not a logico-deductive one. Positivist models of science encourage the notion that researchers stand separate from objects of inquiry in order to minimize the degree to which the act of observation interferes with or contaminates the observation. In interpretive models, this assumption is not so firmly held. The researcher is considered to be an active element of the research process, and the act of research has a creative component that cannot be delegated to an algorithm. Qualitative software programs can be useful in organizing and coding data, but they are no substitute for the interpretation of data. The researcher must make key decisions about which categories to focus on, where to collect the next iteration of data and, perhaps most importantly, the meaning to be ascribed to units of data.

Successful grounded theory research has a clear creative component. Glaser and Strauss were aware of this component and the tension it would create with those who find comfort in trusting an algorithm to produce results. Glaser (1978) used the term "theoretical sensitivity" to describe the essential tension between the mechanical application of technique and the importance of interpretive insight. The tension ultimately proved to be a point of departure between the founders of grounded theory, with Glaser favoring creativity and openness to unanticipated interpretations of data while Strauss (and coauthor Juliet Corbin) became advocates of adherence to formal and prescriptive routines for analyzing data (Locke, 1996). Even so, Corbin and Strauss continued to caution against an overly mechanical application of method:

If the researcher simply follows the grounded theory procedures/canons without imagination or insight into what the data are reflecting-because he or she fails to see what they really indicate except in terms of trivial or well known phenomena-then the published findings fail on this criterion. Because there is an interplay between researcher and data, no method, certainly not grounded theory, can ensure that the interplay will be creative. Creativity depends on the researcher's analytic ability, theoretical sensitivity, and sensitivity to the subtleties of the action/interaction (plus the ability to convey the findings in writing). A creative interplay also depends on the other pole of the researcher-data equation, the quality of the data collected or analyzed. An unimaginative analysis may in a technical sense be adequately grounded in the data, yet be insufficiently grounded for the researcher's theoretical purpose. This occurs if the researcher does not draw on the complete resources of data or fails to push data collection far enough. (Corbin \& Strauss, 1990: 19).

Those new to grounded theory research must become both patient and tolerant of ambiguity, because it is the ongoing interaction between researcher and data that generates the fundament of successful grounded research.

\section{Grounded Theory Is Not Perfect}

In reading reviews of manuscripts that undertake grounded theory, I detect a growing fundamentalism in grounded theory research. That is, there seems to be a growing gap between those who actually engage in grounded theory and those who write about it. The latter group, unsurprisingly, tends toward purist idealism and, as a result, they repeat and reinforce many of the myths I have described above: rigid rules about saturation, mechanical application of technique to data, and clear demarcation between theory and data. The gap between pragmatics and purists has become exacerbated by a proliferation of how-to manuals and textbooks about simplifying and streamlining grounded theory research.

Let me be clear that my intent is not to criticize the emergence of a community of scholars devoted to improving grounded theory methodology. This has occurred in the context of quantitative research as well. There ought to be a healthy tension between pure methodologists and practitioners.

Keep in mind, however, the pragmatic core of grounded theory research. It was founded as a practical approach to help researchers understand complex social processes. It was also designed as a method that might cccupy a pragmatic middle ground between some slippery epistemological boundaries. Because of this genealogy, grounded theory techniques are inherently "messy" (Parkhe, 
1993) and require researchers to develop a tacit knowledge of or feel for when purist admonitions may not be appropriate to their research and may be ignored.

This statement is not an excuse for ignorance of the epistemological and ontological issues surrounding grounded theory methods. Quite the opposite; it speaks to the need for practitioners to know this terrain well, for it is only through understanding the philosophical underpinnings that one can safely navigate the thorny questions of when, for example, one's method is consistent with a particular view of reality. But being aware of one's epistemological position does not justify dogmatism about conducting grounded theory research. Ultimately, questions of when saturation is achieved, how coding should be done, or when counting is appropriate can be resolved pragmatically.

Perhaps an example will clarify these issues of messiness and tacitness. A key point of confusion in grounded theory research is the question of knowing when saturation has occurred during data collection. Because grounded theory research uses iteration and sets no discrete boundary between data collection and analysis, saturation is not always obvious, even to experienced researchers. Yet every submitted manuscript contains a statement that saturation occurred. It is a "box" that must be "checked off" prior to publication.

Deciding saturation has happened takes tacit understanding, which is achieved as much through experience as through a priori criteria. The indeterminate, messy nature of saturation invites a fundamentalist drift toward positivism-the 25 interviews. But, according to Glaser and Strauss, saturation is a practical outcome of a researcher's assessment of the quality and rigor of an emerging theoretical model: "The criteria for determining saturation ... are a combination of the empirical limits of the data, the integration and density of the theory and the analyst's theoretical sensitivity" (1967: 62). The signals of saturation, which include repetition of information and confirmation of existing conceptual categories, are inherently pragmatic and depend upon both the empirical context and the researcher's experience and expertise.

There are other examples of the pragmatic middle road of grounded theory. Fundamentalists often incorrectly describe quantitative approaches as necessarily deductive and grounded theory as inherently inductive. Practically, neither could ever be true. Pierce recognized that pure induction and pure deduction are necessarily sterile. New ideas result from a combination of these fundamental approaches, which he termed "abduction." Abduc- tion "is the process of forming an explanatory hypothesis. It is the only logical operation which introduces any new idea" (Peirce, 1903: 216). Peirce also described abduction as the fallible "flash of insight" that generates new conceptual views of the empirical world. The notion of abduction has become incorporated into grounded theory as "analytic induction," the process by which a researcher moves between induction and deduction while practicing the constant comparative method. Strauss and Corbin noted that induction had been overemphasized in grounded theory research. They observed that whenever researchers conceptualize data, they are engaging in deduction and that effective grounded theory requires "an interplay between induction and deduction (as in all science)" (1998: 137).

In sum, a healthy tension between methodologists and practitioners is desirable, but researchers should try to avoid fundamentalist tendencies in how they approach and, more importantly, evaluate grounded theory research.

\section{Grounded Theory Is Not Easy}

I often get the impression, when reading some of the more egregious examples of how not to do grounded theory research, that the methodology suffers from its apparent simplicity. That is, much like modern art or the sparse prose of Ernest Hemingway, examples of outstanding grounded theory raise the immediate reaction, "Hey, I could do that!" The seamless craft of a well-executed grounded theory study, however, is the product of considerable experience, hard work, creativity and, occasionally, a healthy dose of good luck.

Many of the primary techniques of grounded theory research are developmental. That is, the quality of their application improves with experience. The developmental nature of grounded theory research derives, in part, from individual differences in researchers' ability to interpret patterns in qualitative data (Turner, 1981). Grounded theory is an interpretive process that depends upon the sensitivity of a researcher to tacit elements of the data or meanings and connotations that may not be apparent from a mere superficial reading of denotative content. Many grounded theory researchers describe this interpretion as occurring subconsciously, as a result of their constant "immersion" in the data-an event that some describe as akin to "drowning" (Langley, 1999).

Although the subjective elements of grounded theory research confer an advantage on some individuals, I do not mean to suggest that this bars others from ever conducting grounded theory research. Rather, the advantage some enjoy suggests 
that we who are less gifted with intuitive skills or pattern-perceiving abilities require more course work, training, and experience to acquire these sensitivities. Indeed, the genius of Glaser and Strauss's original methodology is that it outlines a procedure by which formerly tacit processes are made explicit. The apparent simplicity of grounded theory research, however, creates the misperception that it is easy and encourages many without prior experience or education in grounded theory methodology to "have a go." Not surprisingly, the product of such an effort will be similar to the product of a researcher untrained in statistical methods "having a go" at LISREL.

Exemplary research using grounded theory also requires considerable exposure to the empirical context or subject area of research. Contradicting prevalent ideals of scientific detachment from context, the constant comparative method implies an intimate and enduring relationship between researcher and site. Because of this close and longstanding connection, the personality, experience, and character of a researcher become important components of the research process and should be made an explicit part of the analysis (Strauss \& Corbin, 1998).

Two significant consequences flow from this. First, in grounded theory, researchers must account for their positions in the research process. That is, they must engage in ongoing self-reflection to ensure that they take personal biases, world-views, and assumptions into account while collecting, interpreting, and analyzing data. Such continuous reflection is not easy, particularly for those unaccustomed to a model of science in which the researcher is an important focus of the process.

Second, because the somewhat artificial boundary between researcher and research subject is removed, the quality of the contact between researcher and empirical site and the quality of the research produced have a direct relationship. As a result, most high-quality grounded theory research arises from an extensive and ongoing commitment to a line of theoretical research and an empirical site. Consider as an illustration Karl Weick's commitment to studying firefighters' "sensemaking” or Hinings and Greenwood's commitment to studying organizational change in the professions. Such illustrative examples are supported by empirical research showing that the more time researchers spend on-site in organizational contexts, the more they report high levels of "self-learning," and the more their research is cited by peers (Rynes, McNatt, \& Bretz, 1999).

\section{Grounded Theory Is Not an Excuse for the Absence of a Methodology}

This essay was motivated by a recurring problem in manuscripts I see, in which researchers claim to have performed grounded theory research, support their claims with a cursory citations to Glaser and Strauss (1967), and then offer little, if any, description of their methodology. If a revision is granted and the authors are pushed to reveal how the data were collected and analyzed, it becomes clear that the term "grounded theory" was interpreted to mean "anything goes." Data may have been collected randomly, coded by forced application of preexisting conceptual categories, and used to test hypotheses. In sum, the research either ignored or deliberately violated the core procedures and tenets of grounded theory methodology (Locke, 1996).

When I review a paper containing a claim of grounded theory, I check to ensure that, at a minimum, the authors have described their methodology transparently enough to reassure me that they followed core analytic tenets (i.e., theoretical sampling, constant comparison) in generating the data and that I can reasonably assess how the data were used to generate key conceptual categories. I'm also interested to see indicia of the researchers' theoretical sensitivity-their openness to new or unexpected interpretations of the data, the skill with which they combine literature, data, and experience, and their attention to subtleties of meaning. I look for indications of consistency between research questions (and their assumptions about the world and how people come to understand it) and the methods used to answer the questions. Finally, I am very attentive to the researchers' use of technical language in describing their methodology because I believe there is a clear connection between rigor in language and rigor in action.

My observations about the lapses I have observed in reviewing manuscripts may create the unfortunate impression that few exemplary models of grounded theory research exist. This is, of course, simply not true. There are many and, at the risk of offending a large number of exceptional grounded theory researchers, I invite you to read one of my favorites. Isabella's (1990) study on managers' interpretation of processes of organizational change is an outstanding exemplar of grounded theory methodology. The methods section states a research strategy in which the epistemological link between research question and methodology is clear. The process by which interview subjects were identified and selected is made transparent, as is the mode by which raw data were converted to 
conceptual categories. The author offers sufficient detail in the data presented to create a sense of verisimilitude for the reader but also lifts the data by weaving ongoing interpretations, experience, and prior literature into a model of evolving managerial interpretations of organizational change. The study incorporates all of the key analytic tenets and procedures of grounded theory and, at the same time, demonstrates a high degree of theoretical sensitivity in the researcher. It's also a very readable study.

Many other exemplars of grounded theory research-for instance, Sutton (1987), Gersick (1988), and Browning, Beyer, and Shetler (1995)—share the devotion to transparency and rigor described above. I encourage you to read them, both as how-to manuals and as sources of inspiration and motivation to engage in grounded theory research. One of the more satisfying elements of conducting research in management is that, in contrast to the physical sciences, social science research looks at how human invention continually generates new ways of interaction and organization. Researchers can best understand those new modes of interacting and organizing by using a methodology that is attentive to issues of interpretation and process and that does not bind one too closely to long-standing assumptions. Fortunately, that's precisely what grounded theory is.

\section{REFERENCES}

Barley, S. R. 1986. Technology as an occasion for structuring: Evidence from the observations of CT scanners and the social order of radiology departments. Administrative Science Quarterly, 31: 78-109.

Barley, S. R. 1990. The alignment of technology and structure through roles and networks. Administrative Science Quarterly, 35: 61-104.

Bartunek, J. M., Rynes, S. L., \& Ireland, R. D. 2006. What makes interesting research and why does it matter? Academy of Management Journal, 49: 9-15.

Browning, L. D., Beyer, J. M., \& Shetler, J. C. 1995. Building cooperation in a competitive industry: SEMATECH and the semiconductor industry. Academy of Management Journal, 38: 113-151.

Burrell, G., \& Morgan, G. 1979. Sociological paradigms and organisational analysis: Elements of the sociology of corporate life. London: Heinemann.

Coase, R. 1988. The firm, the market, and the law. Chicago: University of Chicago Press.

Corbin, J., \& Strauss, A. 1990. Grounded theory research: Procedures, canons and evaluative criteria. Qualitative Sociology, 13: 3-21.

Gephart, R. P. 2004. Qualitative research and the Acad- emy of Management Journal. Academy of Management Journal, 47: 454-462.

Gersick, C. J. G. 1988. Time and transition in work teams: Toward a new model in group development. Academy of Management Journal, 31: 9-41.

Glaser, B. G. 1978. Theoretical sensitivity. Mill Valley, CA: Sociology Press.

Glaser, B. G. 1992. Basics of grounded theory analysis. Mill Valley, CA: Sociology Press.

Glaser, B. G., \& Strauss, A. L. 1967. The discovery of grounded theory: Strategies for qualitative research. New York: Aldine.

Goulding, C. 2002. Grounded theory: A practical guide for management, business and market researchers. London: Sage.

Husserl, E. 1969. Cartesian meditations: An introduction to phenomenology [D. Cairsn, trans.]. The Hague: Martinus-Nijhoff.

Isabella, L. A. 1990. Evolving interpretations as change unfolds: How managers construe key organizational events. Academy of Management Journal, 33: 7-41.

Krippendorff, K. 2003. Content analysis: An introduction to its methodology (2nd ed.). Thousand Oaks, CA: Sage.

Langley, A. 1999. Strategies for theorizing from process data. Academy of Management Review, 24: 691710.

Locke, K. 1996. Rewriting the discovery of grounded theory after 25 years? Journal of Management Inquiry, 5: 239-245.

Locke, K. 2001. Grounded theory in management research. London: Sage.

Martin, P. Y., \& Turner, B. A. 1986. Grounded theory and organizational research. Journal of Applied Behavioral Science, 22: 141-157.

Morgan, G., \& Smircich, L. 1980. The case for qualitative research. Academy of Management Review, 5: 491-500.

Moustakas, C. 1994. Phenomenological research methods. Thousand Oaks, CA: Sage.

Parkhe, A. 1993. "Messy" research, methodological predispositions and theory development in international joint ventures. Academy of Management Review, 18: 227-268.

Peirce, C. S. 1903. The essential Pierce: Selected philosophical writings, vol. 2. Bloomington: Indiana University Press.

Rynes, S. L., McNatt, D. B., \& Bretz, R. D. 1999. Academic research inside organizations: Inputs, processes, and outcomes. Personnel Psychology, 52: 869-898.

Schutz, A. 1972. The phenomenology of the social world. London: Heinemenn Educational Books.

Spindler, G., \& Spindler, L. 1982. Roger Harker and 
Schonhausen: From the familiar to the strange and back. In G. Spindler (Ed.), Doing the anthropology of schooling: 21-46. New York: Holt, Rinehart \& Winston.

Strauss, A., \& Corbin, J. 1998. Basics of qualitative research: Techniques and procedures for developing grounded theory (2nd ed.). Thousand Oaks, CA: Sage.

Sutton, R. I. 1987. The process of organizational death:
Disbanding and reconnecting. Administrative Science Quarterly, 32: 542-569.

Turner, B. A. 1981. Some practical aspects of qualitative data analysis: One way of organizing the cognitive processes associated with the generation of grounded theory. Quality and Quantity, 15: 225-247.

Wimpenny, P., \& Gass, J. 2000. Interviewing in phenomenology and grounded theory: Is there a difference? Journal of Advanced Nursing, 31: 1485-1492. 
Copyright of Academy of Management Journal is the property of Academy of Management and its content may not be copied or emailed to multiple sites or posted to a listserv without the copyright holder's express written permission. However, users may print, download, or email articles for individual use. 